\title{
Post-dissection Survival, Conservation and Reutilization of Clarias batrachus (Linnaeus, 1758) Male Broodstock
}

\author{
Bhushan N. Sanap ${ }^{1}$, Rashmi S. Ambulkar ${ }^{1}$, Smital D. Kamble $^{1}$ and C.S. Chaturvedi ${ }^{2}$ \\ ${ }^{1}$ ICAR-Central Institute of Fisheries Education, Versova, Mumbai - 400 061, India \\ ${ }^{2}$ NationalBureauofFishGeneticResources, Lucknow-226002, India \\ *Corresponding author
}

\section{A B S T R A C T}

\section{Keywords \\ Fish surgery, Clarias batrachus, Fish dissection, Broodstock survival, Broodstock, Fish conservation \\ Article Info \\ Accepted: 17 January 2018 Available Online: 10 February 2018}

The present study is an attempt with an objective to achieve the survival of the male fish even after dissection and surgery is done corroborative to human surgery. Three experiments on males after dissection were stitched with absorbable surgical thread (T1); stitched with normal cotton thread (T2); and (T3) was the control was unstitched. Fishes were successfully operated for removal of testes. Swimming behaviour and feed intake were very normal in T1 and T2 while abnormal and reduced feed intake in T3. The wounds were completely healed on the tenth day and the stitched marks were very faint by the $20^{\text {th }}$ day. Survival in T1 and T2 was $100 \%$ while in T3 was $62.5 \%$. In usual process of dissection, themale is killed. Sometimes testes are found not fully ripe and unable to fertilise the eggs resulting male fish is dead and unnecessarily killed. As this leads to a reduction in male population it indirectly creates a danger to the sustainability of its population. Present study highly contributes toconservation of this fish. Moreover, survived fishes can be reutilised for Clarias batrachus fattening and selling although it cannot be used for breeding.

\section{Introduction}

The catfish, Clarias batrachus ordinarily known as "Asian catfish" (Magur), is an endemic fish of India available in almost all its river systems, lakes and ponds. This fish serve as one of the significant food sources in the country. The palate and curative attributes of the fish has captured the high market demand (Debnath, 2011; Hossain et al., 2006). It is also eye catching to the consumers due to the characteristics of the fish that it can remain fresh and alive out of water for a considerable time due to its air-breathing nature. However, it is eminent that $C$. batrachus populace have been awfully diminished during last two decades because of overfishing and habitat diversifications (Khedkar et al., 2010). To accomplish the market demand, farmers in West Bengal during the 1980s, endeavoured to develop technologies for seed production. Relatively this was favourable, but the low fecundity of the females accompanying with early mortality during seed production became leading impediments associated with the 
culturing of this fish in India (Hossain et al., 2006).

To gratify the constant demands for supply of C. batrachus, a morphologically analogous fish, Clarias gariepinus, captivated the heed of aquaculturists and paved the way for its unapproved introduction in Indian waters (Thakur, 1998). However, once instigated, the hostile carnivorous nature and accelerated growth rate of $C$. gariepinus endorsed its establishment in about all river systems in India. This also evidently led to further acute downturn in populace of $C$. batrachus (Thakur, 1998; Khedkar et al., 2010, 2016). Over-harvesting of $C$. batrachus populace also persisted to have an influence on the genetic assortment of this species. There was the occurrence of catfishes in good number in A \& $\mathrm{N}$ islands during pre-tsunami period however their abundance has been drastically declined in the post-tsunami due to the intrusion of seawater in the paddy fields/irrigation ponds which affected their local migration and breeding grounds (Chaturvedi et al., 2013).

During the present study, the information collected from the local fish farmers insisted that fertilisers and pesticides used in paddy fields were the reason for the destruction of the species since $C$. batrachus were abundantly found in this habitat. In the induced breeding of $C$. batrachus stripping of milt from male testis is not possible which forces to sacrifice male fish for the acquisition of milt. However, this leads to a reduction of number of males of the species. The primary objective of the study was to achieve the survival of the dissected fish after the removal of the both the testes. The surgery is based upon the concept alike in the human surgery where study on the removal of only one testis and regrowth of the removed testis is ongoing. Hence, the present study is an attempt to achieve the survival of the male fish even after dissection.

\section{Materials and Methods}

The study was carried out at Central Institute of Fisheries Education, Mumbai. Twenty-four male fishes were used for the study; however, these fishes were dissected for the spermatozoa cryopreservation. There were three experiments carried out T1 and T2 while T3 was the control. In the first experiment the males dissected were stitched with the absorbable surgical thread (T1) and in the second experiment, males were stitched with the normal cotton thread (T2) with the zero size needles. In the control (T3), the males dissected were not stitched and released in the tank without stitching for observing the survival. In this experiment for breeding purpose males were operated in such a way that it made easy for stitching the cut portion while operation. At the time of dissection fish was covered with black wet cloth on the dorsal side from the head portion up to tail, especially the eyes of the fish were covered properly to lessen the movement of the fish. The tail was held firmly to avoid movement of fish. Live fish was held upside-down, then, $2 \mathrm{~cm}$ above the genital papilla, a straight slit was cut up to $2-3 \mathrm{~cm}$ on the abdomen using scissors and cutter (Fig. 2). The length of the slit depended upon the length of the fish. The operation was done for the removal of testis for the breeding purpose (Fig. 4). While removal of testis the care was taken that other organs were not damaged during the whole procedure of surgery. Pair of testes were removed and immediately kept in $0.9 \%$ saline solution for further use. 3-4 stitches were done depending upon the length of the slit (Fig. 3). Each stitch was separate from another stitch and roughly $1 \mathrm{~cm}$ distance was kept between each stitch (Fig. 5 and 6). After stitching, the Mupiban ointment was applied over the stitched slit for the faster wound healing. The fishes were then released in FRP tanks, with $30 \mathrm{~cm}$ depth of water to avoid energy loss, since $C$. batrachus is the air breather and often comes to the surface for 
air-breathing. After 2 days of stitching, fishes have treated with Mupiban ointment again for the faster healing of wounds (Fig 9). Fishes were observed for the significant differences in the operated area and were reported for 20 days after stitching. Survival of the fishes was recorded. In the control (T3), fishes dissected were released in the tank unstitched and without application of mupiban ointment. During the operation, minimum handling was done to avoid stress and injury to the fish.

\section{Results and Discussion}

The technique used for the dissection was unique. It was observed that closing the eyes of the fish reduced the movement and holding the tail almost stopped the body movement which paved the way for surgery. Usually, for removal of the testis, the fish is needed to be killed (Fig. 1), but the unique way of dissection by slit cutting (Fig. 2) and the use of cloth with eyes covered and restricting the movement of tail allowed to remove the testis and perform the successful surgery. Slit cut of 3-4 $\mathrm{cm}$ makes easy removal of testes (Fig 3 and 4). The survival in both the experiments was $100 \%$. There was no mortality. The slit of the abdomen started healing after 2 days in surgical thread stitched fishes also most of the stitches were disappeared and the slit was found joined (Fig. 7), however, no healing was found in the fishes stitched with normal cotton thread (Fig. 8). Experimental fishes were found behaving normally after the operation. In the treatment $\mathrm{T} 1$, on the seventh day, the sutures were fully dissolved and the

whole slit was found joined (Fig. 10). In T2 one or two stitches were found remaining and other stitches were released from the fish body, due to their swimming movement however the slit was joined and the knot was found loose. In T2, in some fishes, it was found that all the cotton stitches were released but there were blisters formed with a pus formation (Fig. 12). The remaining knots were removed manually which resulted with no more blisters. On the tenth day, the wounds were completely healed with no more blood stains however the stitched marks were visible (Fig. 12 and 14). A significant difference was found between the healing process of stitches with surgical sutures and stitches with cotton thread. In the cotton thread, healing process started on the fourth day and in surgical sutures started on the second day. On the $10^{\text {th }}$ day, the wound was completely healed in $\mathrm{T} 1$ and $\mathrm{T} 2$. On the $20^{\text {th }}$ day the marks were almost very faint (Fig. 15, 16). In the control, the survival was $62.5 \%$ and the process of wound healing was very slow. Abdominal other organs were protruded out of the body causing severe damage which caused mortality. Hence fishes were needed to keep with very less density in one tank to avoid damages. It was also observed that after surgery fishes in $\mathrm{T} 1$ and $\mathrm{T} 2$ were seen absolutely normal in the swimming behaviour and intake of feed. However, in the control (T1), swimming behaviour was abnormal due to the wounds and feed intake was lessened. The results in tabular form are shown in table 1 .

Table.1

\begin{tabular}{|l|l|l|l|}
\hline Sr. No. & Treatments & Description & Survival \\
\hline $\mathbf{1}$ & T1 & Stitching with surgical thread & $100 \%$ \\
\hline $\mathbf{2}$ & T2 & Stitching with cotton thread & $100 \%$ \\
\hline $\mathbf{3}$ & T3 & Unstitched (control) & $62.5 \%$ \\
\hline & & & \\
\hline
\end{tabular}




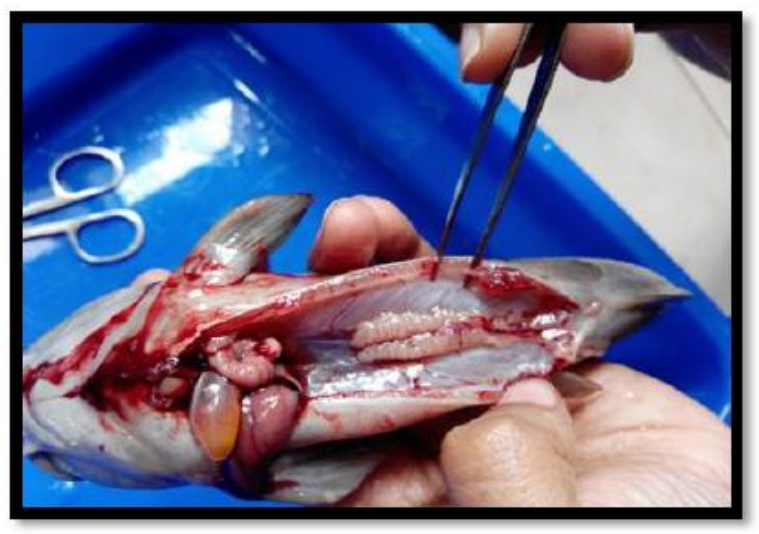

Fig 1 Usual dissection by killing the fish

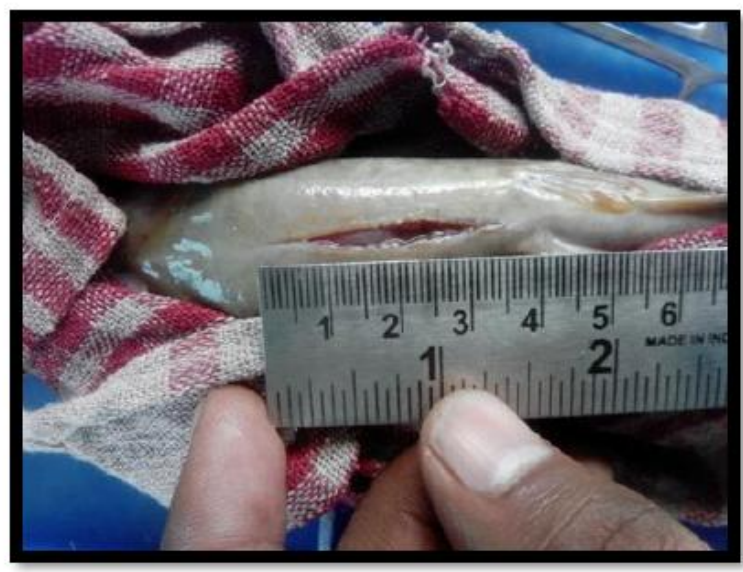

Fig 3 length of the slit $\quad(3-4 \mathrm{~cm})$

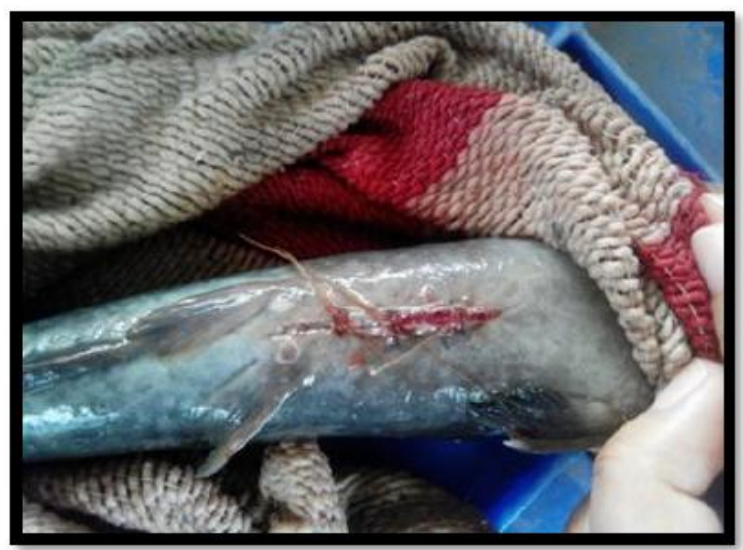

Fig 5 Stitches with surgical thread (T1)

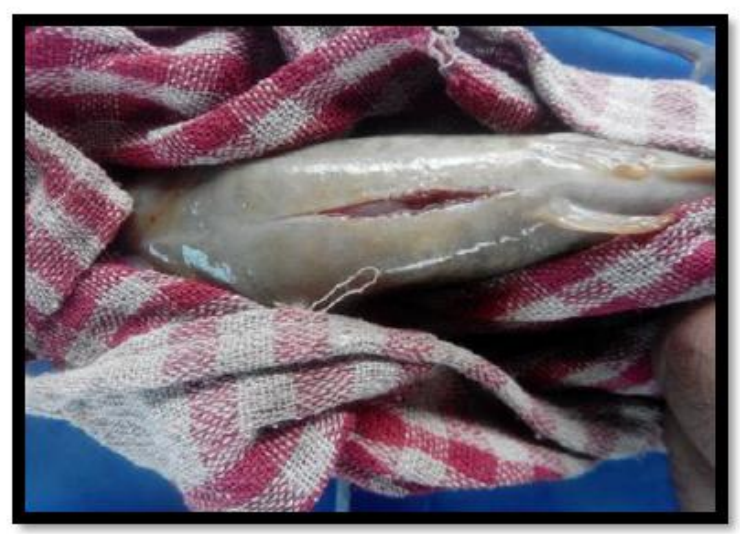

Fig 2 Slit cutting using wet cloth with covered eyes

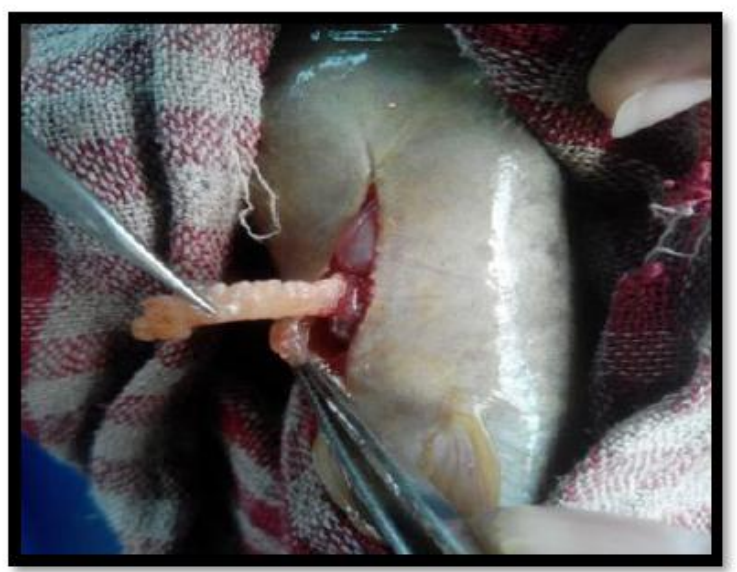

Fig 4 Removal of testis

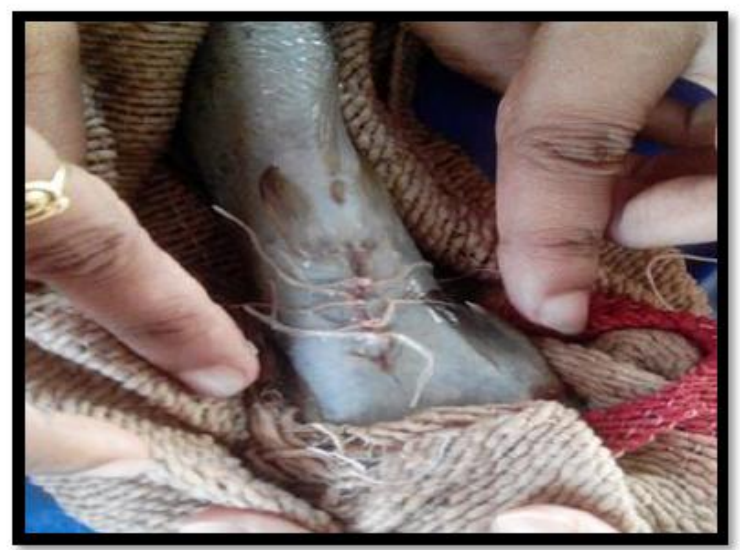

Fig 6 Stitches with normal cotton thread (T2) 


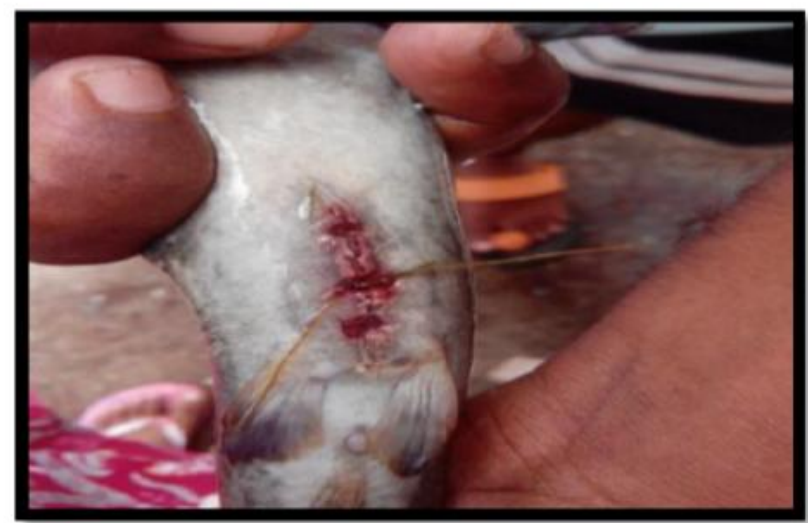

Fig 7 Wound healing on second day (T1)

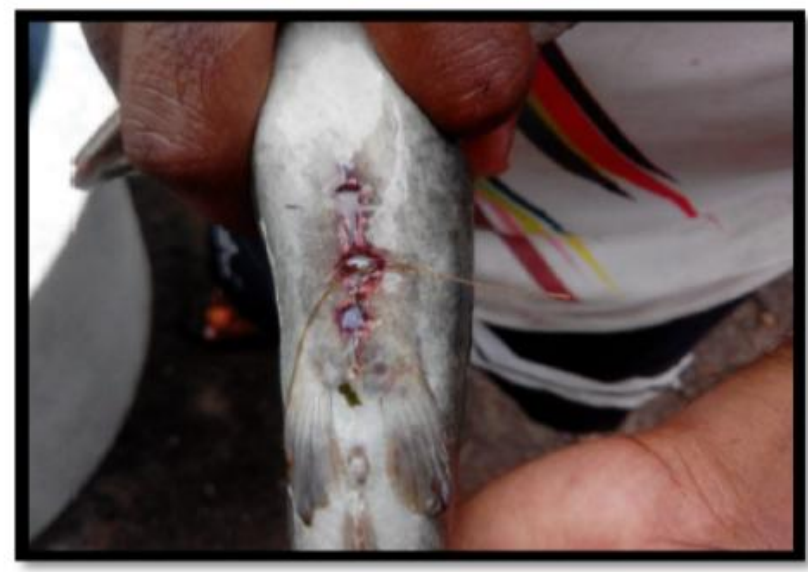

Fig 9 Treatment with ointment on 2nd day

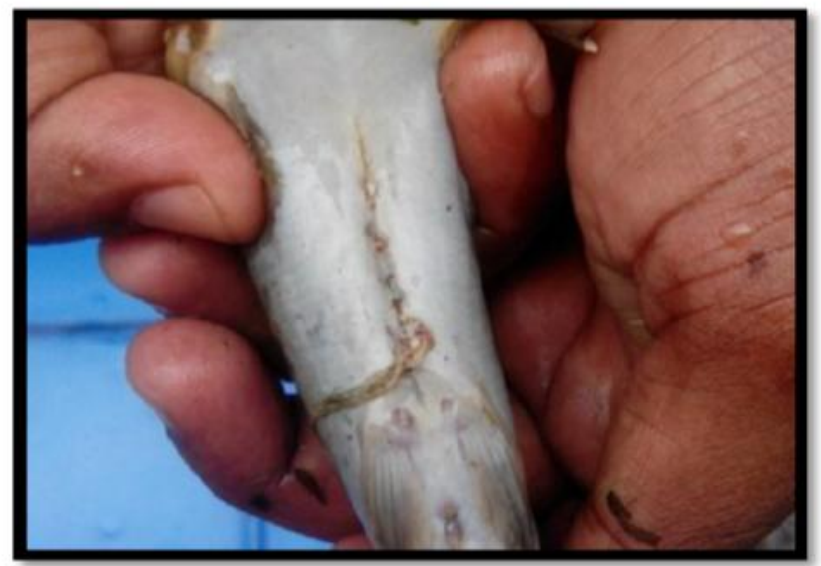

Fig 11 Wound healing on 7th day

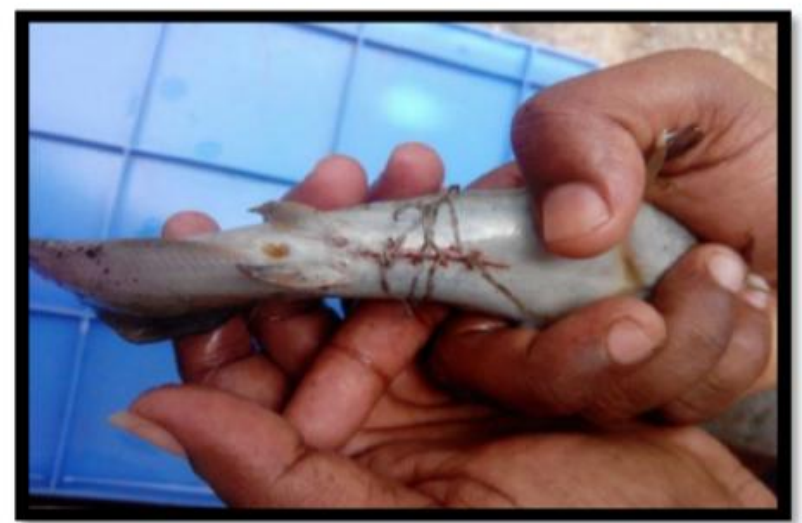

Fig 8 Wound healing on second day (T2)

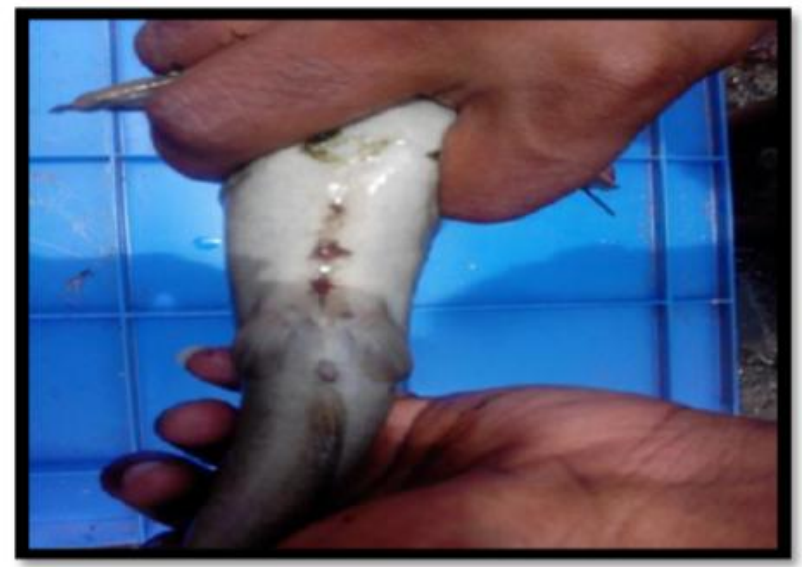

Fig 10 Wound healing on 7th day

(T1)

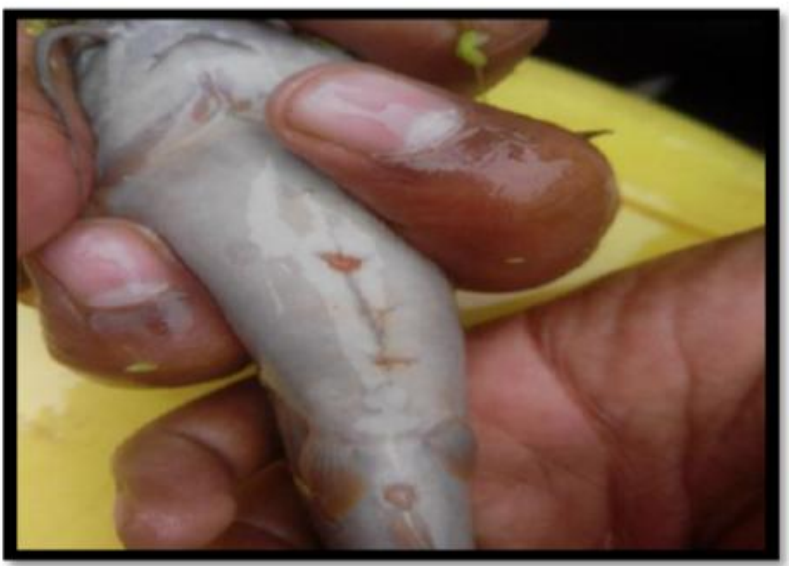

Fig 12 Blisters with pus formation in T2 


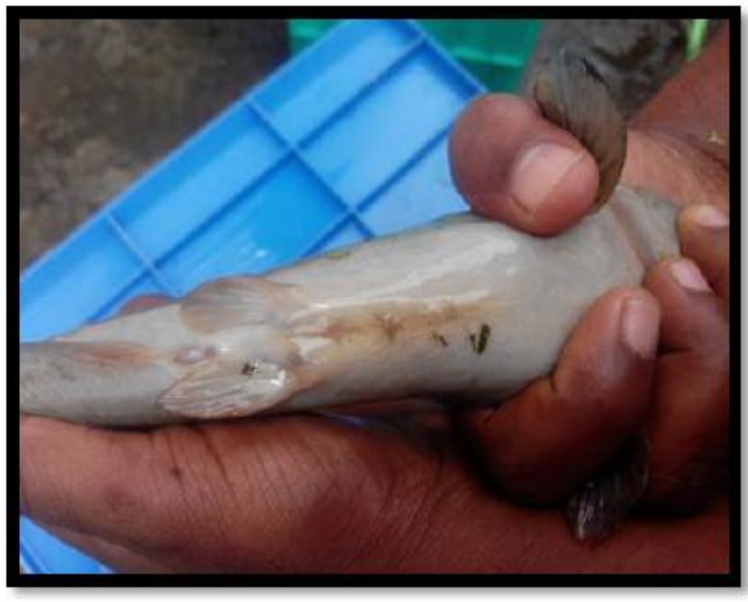

Fig 13 Wound healing on 10th day (T1)

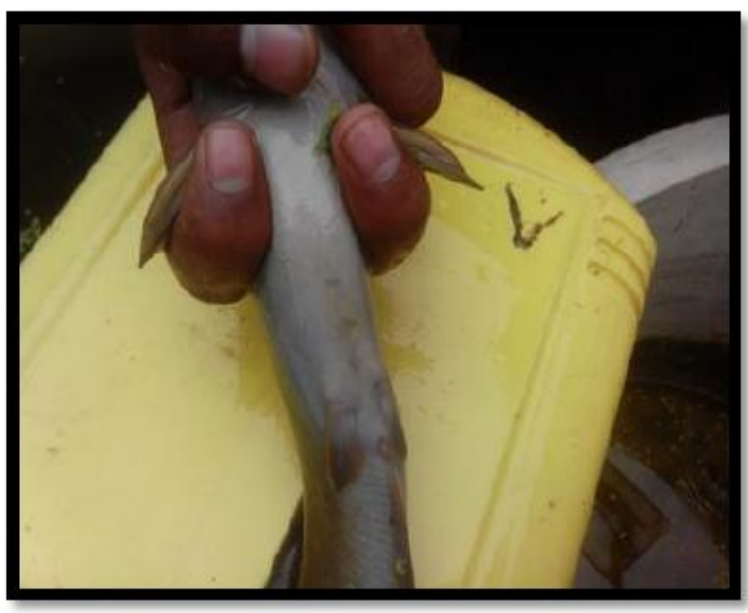

Fig 15 Complete wound healing on 20th day (T1)

The stitches of surgical sutures (T1), wound were completely healed on the seventh day and in the cotton thread stitches (T2), on the tenth day with $100 \%$ survival in the both the treatments. In the present study, it was observed in the control (T1) that abdominal organs were protruded out during swimming which caused damage to them and also the damage was caused by the wounds of the cut slit. Borah and Gogoi (2015) had reported that after removal of testis of $C$. batrachus by dissection it has self-healing capacity through

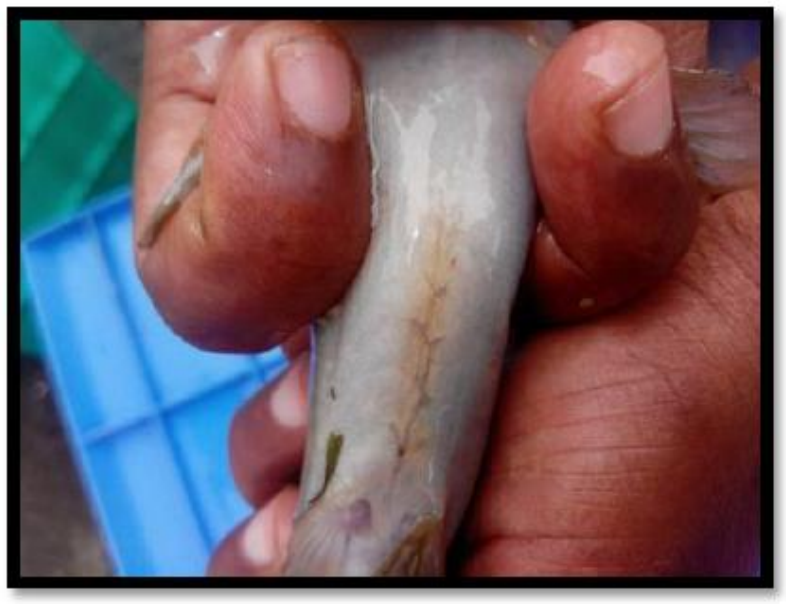

Fig14 Wound healing on 10th day (T2)

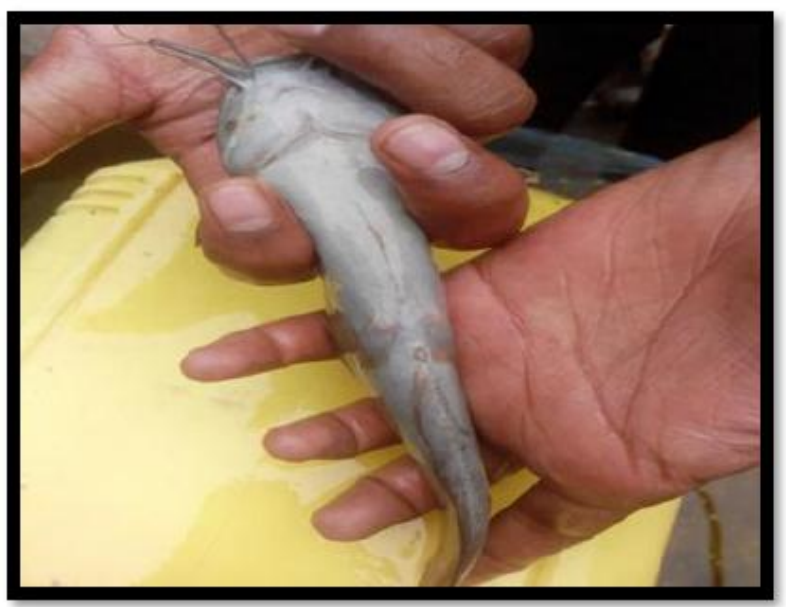

Fig 16 Complete wound healing on 20th $\operatorname{day}(T 2)$

tissue regeneration without any stitching or medication, however, the survival found in their study was $90 \%$ and the cut slit while dissection was almost joined in 13 days but completely healed and joined in 30 days. This is in agreement with the present study that fish survives even after dissection, however, the mortality was little more in the control. Throughout the course of the medical history, sutures have been used to expedite and enhance the wound closure and hasten the healing which is still the most common 
method of wound closure, it also backs up to progress the clinical outcomes and caters mechanical support to a wound to build the optimal environment for wound healing (Kjaergard, 2001).

The initial role of the sutures is to seal the wound and protect it from pathogens (Yang et al., 2011). In humans, normal wound healing response sets out the moment the tissue is injured, the platelets come into the contact with exposed collagen and other elements of extracellular matrix which activates the platelets to release platelet-derived growth factor (PDGF) and transforming growth factor beta (TGF-beta) following the neutrophils entering the wound sites and begin the critical task of phagocytosis to remove foreign materials, bacteria and damaged tissue (Diegalmann and Evans, 2004), which supports the findings of the present study where there are blisters of pus formation which may be due to presence of cotton thread trapped at the healing site. Once the wound site is cleansed out, fibroblasts migrate in to begin the proliferative phase and deposit new extracellular matrix where the new collagen matrix then becomes cross-linked and organized during the ultimate remodelling phase of the impaired site (Diegalmann and Evans, 2004). Collagen type I is ruling in the scar tissue of skin (Prockop and Kivirikko, 1995). Collagen in the skin of C. batrachusconstitutes of collagen type I, which consists of two $\alpha$ chains $(\alpha-1$ and $\alpha-2)$ and $\beta$ chain (Leong et al.2015), which clarifies the faster wound healing capacity of C. batrachus.

Hence concluded, in the usual process of dissection, male fish of $C$. batrachus is killed. Sometimes testes are found not fully ripe hence not capable of producing good amount and quality of milt for fertilisation of eggs. However, while dissection, by the time this is known to the farmer, fish is unnecessarily killed. As this leads to reduction in male population of this fish and indirectly creates danger to the sustainability of its population. Therefore, the present study highly contributes for conservation of this fish. Other advantages of the study are, survived fishes can be used for selling in the market although it cannot be used for breeding purpose. This can help the farmers for increment in their income. Individual male fish receives the chance to live for the entire life. Moreover the survived fishes can be used further for $C$. batrachus fattening.

\section{Acknowledgement}

The authors express their deep sense of gratitude to the Director, ICAR-Central Institute of Fisheries Education, Mumbai for providing the necessary facilities for carrying out the research and career advancement.

\section{References}

Borah and Gogoi, 2015. An observation on the amazing self-healing capacity of catfish Magur (Clarias batrachus). International Journal of Fisheries and Aquatic Studies, 2(4), pp.38-40.

Chaturvedi, C.S., Roy, S.D., Nagesh, R. and Pandey, A.K., 2013. Post-tsunami abundance of Clarias batrachus and Heteropneustes fossilis in Andaman and Nicobar Islands. Journal of Experimental Zoology, India, 16(2), pp.491-494.

Debnath, S., 2011. Clarias batrachus, the medicinal fish: An excellent candidate for aquaculture and employment generation. In: International Conference on Asia Agriculture and Animal. IPCBEE (13), Singapore (pp. 32-37).

Hossain, Q., Hossain, M.A. and Parween, S., 2006. Artificial breeding and nursery practices of Clarias batrachus 
(Linnaeus, 1758). Scientific World, 4(4), pp.32-37.

Khedkar, G.D., Reddy, A.C.S., Mann, P., Ravinder, K. and Muzumdar, K., 2010. Clarias batrachus (Linn. 1758) population is lacking genetic diversity in India. Molecular biology reports, 37(3), pp.1355-1362.

Khedkar, G.D., Tiknaik, A.D., Shinde, R.N., Kalyankar, A.D., Ron, T.B. and Haymer, D., 2016. High rates of substitution of the native catfish Clarias batrachus by Clarias gariepinus in India. Mitochondrial DNA Part A, 27(1), pp.569-574.
Kjaergard, H.K., 2001. Suture support: Is it advantageous? The American journal of surgery, 182(2), pp.S15-S20.

Prockop, D.J. and Kivirikko, K.I., 1995. Collagens: molecular biology, diseases, and potentials for therapy. Annual review of biochemistry, 64(1), pp.403-434.

Thakur, N.K., 1998. A biological profile of African catfish Clarias gariepinus and impact of its introduction in Asia. Fish Genetics and Biodiversity Conservation. Natcon Publications, Muzzafarnagar (UP) India, pp.275292.

\section{How to cite this article:}

Bhushan N. Sanap, Rashmi S. Ambulkar, Smital D. Kamble and Chaturvedi, C.S. 2018. Postdissection Survival, Conservation and Reutilization of Clarias batrachus (Linnaeus, 1758) Male Broodstock. Int.J.Curr.Microbiol.App.Sci. 7(02): 2010-2017. doi: https://doi.org/10.20546/ijcmas.2018.702.240 